NASA Technical Memorandum 102370

\title{
Structural Behavior of Composites With Progressive Fracture
}

Levon Minnetyan

Clarkson University

Potsdam, New York

Christos C. Chamis and Pappu L.N. Murthy

Lewis Research Center

Cleveland, Ohio

January 1990

\section{NASA}




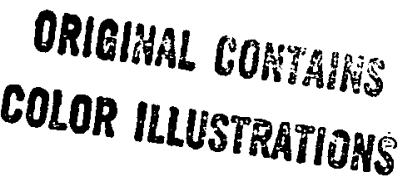

\section{STRUCTURAL BEHAVIOR OF COMPOSITES WITH PROGRESSIVE FRACTURE}

\author{
Levon Minnetyan \\ Clarkson University \\ Potsdam, New York 13676 \\ Christos C. Chamis and Pappu L.N. Murthy \\ National Aeronautics and Space Administration \\ Lewis Research Center \\ Cleveland, Ohio 44135
}

\section{Summary}

Structural characteristics such as natural frequencies and buckling loads with corresponding mode shapes were investigated during progressive fracture of multilayer, angleplied polymer matrix composites. A computer program was used to generate the numerical results for overall mechanical response of damaged composites. Variations in structural characteristics as a function of the previously applied loading were studied. Results indicate that most of the overall structural properties were preserved throughout a significant proportion of the ultimate fracture load. For the cases studied, changes in structural behavior began to occur after 70 percent of the ultimate fracture load had been applied. However, the individual nature of the structural change was rather varied depending on the laminate configuration, fiber orientation, and the boundary conditions.

\section{Introduction}

The overall dynamic behavior and stability of partially damaged composite structures is of interest from two perspectives: (1) the need to predict whether a structure or component will remain safe and perform the required function when local damage or fracture occurs at various locations and (2) the need to use dynamic test response measurements with a structural identification procedure to assess the total damage sustained because of previous loading or environmental effects. The free-vibration response of damaged angle-plied fiber composites has been studied in the past, both experimentally and by computational simulation (refs. 1 and 2). Although these past studies of structural response for damaged composites have shown remarkable agreement between experimental and computational predictions, proper assembly of the com- putational model for the simulation of load-induced damage has required considerable judgment and intuition. In a parallel course of investigation, a computational and experimental program was launched at NASA Lewis Research Center to study the progressive fracture of fiber composite laminates with regard to their performance in aerospace propulsion structures (refs. 3 and 4). The computational procedure to simulate progressive fracture has resulted in the computer code CODSTRAN (Composite Durability Structural Analyzer). CODSTRAN has been validated by an experimental program for fiber composites subjected to progressive fracture under axial loading.

The purpose of this report is to unify the computational tools that have been developed at NASA Lewis for the prediction of progressive damage and fracture with efforts in the prediction of overall response of damaged composite structures. In the present approach, the computational finite element model for the damaged structure is constructed by the computer program as a byproduct of the analysis of progressive damage and fracture. Thus, a single computational investigation is able to predict progressive fracture and the resulting variation in structural properties of angle-plied composites. The combined numerical procedure is amenable to development as a nondestructive evaluation method for the structural integrity of multi-ply composites.

\section{Method of Computation}

For this analysis, the ICAN (Integrated Composite Analyzer) and MHOST programs (refs. 5 to 7) were combined to form CODSTRAN in order to simulate progressive damage in composite structures. ICAN is capable of determining the ability of the composite to withstand various stresses and strains, and it predicts all possible internal damage and fracture 
in the composite material. Input parameters of ICAN include the definition of the material system, fiber volume ratio, laminate configuration, fabrication factors, and environmental conditions such as temperature and humidity. The output parameters include composite hygral, thermal, and mechanical properties that are needed to perform structural and stress analyses in the specified service environment. ICAN utilizes a resident data bank that contains the properties of a variety of fiber and matrix constituent materials and has provisions to add new constituents as they become available.

The recursive use of ICAN with a linear structural analysis program results in a piecewise linear incremental loading analyzer with equilibrium checks and iterations at each load increment (CODSTRAN). In the past, ICAN has been combined with various stress analyzers such as NASTRAN (ref. 8) to form the CODSTRAN program. The current version of CODSTRAN uses MHOST (ref. 7) as the structural analysis module because the MHOST quadrilateral shell element can accept the composite material constitutive relations defined by ICAN to produce the finite element properties.

Fourteen distinct failure modes are checked by ICAN at each load increment during a CODSTRAN analysis stage. The failure modes that are monitored include the failure criteria associated with the positive and negative limits of all six stress components, a modified distortion energy failure criterion, and a relative rotation check. The CODSTRAN incrementalloading procedure uses an accuracy criterion based on the maximum number of nodes that are allowed to be damaged during the application of a load increment. In this particular study, four nodes were allowed as the maximum number of nodes to be damaged or fractured during a load increment. If too many nodes were damaged or failed in a given load increment, the incremental loads were reduced and the analysis was repeated. Otherwise, equilibrium iterations were conducted, as required, under the same load increment until the applied loads were balanced by the composite stresses. During analysis, structural stiffness was reduced at damaged nodes whenever the ICAN module determined that it was appropriate. When a node failed completely, that node was deleted and new detached nodes were created at the same point for the remaining adjacent finite elements. This process effectively simulates the through-the-thickness fracture of the composite. Whenever two adjacent nodes of a finite element failed, that element was removed from the mesh.

For the current study, the CODSTRAN program was modified to conduct a free-vibration analysis and an eigenvalue buckling analysis at certain stages. Eigenvalue analyses were first conducted before loading. Later during progressive fracture computations, the eigenanalyses were repeated after each equilibrium stage on the current damaged state of the structure. The modifications to CODSTRAN consist of the addition of subroutines that prepare the input data for freevibration and buckling analyses and that reference the MHOST module to conduct the eigenanalyses whenever equilibrium is reached during the incremental-loading procedure. The result is a new version of CODSTRAN that conducts the previously verified progressive fracture investigation in composite laminates and that, in addition, carries out free-vibration and linear buckling analyses during the progression of damage to determine the effects of damage on overall structural behavior.

\section{Example Composite Structures and Numerical Results}

An intermediate stiffness T-300/Epoxy composite structure was selected for the initial investigations. A simple planar computational model with a small rectangular central notch was used (fig. 1). The symmetric laminate for the present study has fiber orientations of $\left[ \pm 15^{\circ}\right]_{s}$, with zero degrees corresponding to the axial loading direction. A rectangular plate that was 4 in. long, 3 in. wide, and 0.13 in. thick was considered. Two support conditions were used:

(1) Simple support on the 3-in. edges, but no support (free)

on the longer edges along the axial direction

(2) Simple support on all four edges

In each case the plate was analyzed under a gradually applied uniform axial tensile loading. Progressive damage and fracture were monitored as the applied loading was increased. As the composite structure deteriorated under loading, its overall response properties, such as natural frequencies and buckling loads with their associated mode shapes, were expected to degrade as well. The buckling load was calculated based on a uniformly distributed compressive load applied at the ends of the plate in the axial direction.

Figure 2 shows, for support condition 1, the decline in the first three natural frequencies and in the fundamental buckling load as a function of the load endured by the plate. On the ordinate in figure $2, F_{i} / F_{i o}$ denotes the $i^{\text {th }}$ natural frequency normalized with respect to its undamaged value. Similarly, $B_{1} / B_{10}$ denotes the normalized value of the first buckling load. There is no perceivable degradation in the plotted structural properties for up to about 70 percent of the ultimate fracture loading. This is consistent with the absence of any internal damage in the composite plate up to the same load level. After damage, both the natural frequency and the buckling load are reduced significantly (fig. 2). Free-vibration and buckling eigenvector mode shapes are similarly affected because of damage and fracture.

Figure 3 shows the mode shape fringes for the first three free-vibration modes and the first buckling mode before loading. Figures 4 and 5 show the same mode shapes for 94 and 97 percent of the ultimate fracture load, respectively. As expected, there are some changes in the overall structural behavior after the application of such high levels of loading. Nevertheless, the structure still behaves as a continuous unit in spite of a significant amount of internal damage and fracture. However, the free-vibration and buckling mode shapes are not completely symmetrical even though the composite laminate fiber orientations are symmetrical with regard to axial loading. 
The lack of complete symmetry in the mode shapes is mainly due to the orientation of the outer fiber layers having a much greater influence on the flexural properties of the laminate.

Figure 6 shows the degradation of buckling load and natural frequencies for the same plate, but now simply supported on all four edges (support condition 2). The normalized plots for overall mechanical properties depicted in figure 6 are similar to those corresponding to support condition 1 (depicted in fig. 2). One significant difference is that the buckling load increases above the original undamaged value just before ultimate failure. This effect is caused by the fragmentation of the plate structural behavior under the combined influences of the buckling load and the boundary conditions. Because of local degradation, a partial flexural hinge forms at the center of the plate along the existing notch, effectively separating the plate into two halves from an elastic stability viewpoint. When the two halves of the plate behave independently, the buckling load is increased. Also, after a certain amount of loading, the second and the third vibration frequencies switch their mode shapes. These effects are examined further in later paragraphs with the help of the corresponding mode shape fringes.

Figure 7 shows the mode shapes for the first three freevibration modes and the first buckling mode before loading. Because of the additional restraints at the boundaries for support condition 2 , the mode shapes are more significantly affected by the boundary conditions. For that reason, the first vibration mode (fig. 7(a)) and the fundamental buckling mode (fig. 7(d)) are virtually identical, indicating that in this case boundary conditions, rather than external effects, have the controlling influence on structural behavior. It is also noteworthy that the second and the third vibration mode shapes are now more obviously affected by composite laminate fiber orientations that make the plate significantly more stiff in the axial direction. As a result and in spite of the transverse central notch in the plate, the vibration mode producing a transverse full wave, mode 2 , is lower in frequency than the vibration mode producing a longitudinal full wave, mode 3 . The mode 3 natural frequency is almost twice the mode 2 frequency.

Figure 8 shows the same mode shapes for support condition 2, for 91 percent of the ultimate fracture load. At 91 percent of loading, the central notch extends in the transverse direction when the elements adjacent to the notch fail. There is some decoupling of the two sides of the plate separated by the notch as indicated by the reduction of modal symmetry across the center of the plate. This reduction in symmetry may be observed in vibration modes 1 and 3 and in the buckling mode. The overall mode shape configurations for the second and third free-vibration frequencies remain as they were prior to loading. There is some reduction in all three natural frequencies and the buckling load. However, because of the extension of the central notch, the third natural frequency is reduced more significantly than the second natural frequency: the vibration frequency of mode 3 is now only 18 percent higher than the vibration frequency of mode 2 .
Figure 9 shows the mode shapes for support condition 2, for 94 percent of the ultimate fracture load. At this loading stage additional elements on either side of the central notch as well as the nodes at both ends of the notch have failed. As a result, the natural frequency corresponding to the vibration mode with the longitudinal full wave has been reduced below that of the mode with the transverse full wave. In other words, the second and third vibration modes have switched the order of their natural frequencies. Nevertheless, the structure still appears to behave as a continuous unit in spite of a significant amount of internal damage and fracture.

The buckling mode, as depicted in figure 9(d), shows significant decoupling of the two sides of the plate separated by the central notch. Because of boundary restraints, structural decoupling reduces the effective buckling length, and consequently, the fundamental buckling load at this advanced stage of local damage increases significantly.

At very high levels of loading, structural damage becomes pervasive at all parts of the plate, which ceases to behave as a continuous structure. Parts (a) and (b) of figure 10 show, respectively, the shapes of the third vibration mode and the buckling mode after 98 percent of the ultimate fracture load has been applied. The first two vibration modes are not shown because they are trivial cases with zero eigenvalues and involve only disjoint elements similar to those in the buckling mode. The third vibration mode (fig. 10(a)) involves only a small portion of the plate that appears to have been spared complete degradation because of its remoteness from the applied loading and because of the stress relief provided by the existing central notch. Figure $10(\mathrm{~b})$ indicates that at this highly damaged stage the first buckling mode computed by the analysis module no longer represents a structural response characteristic. This buckling mode has no significance other than to indicate that the structure has completely lost its integrity.

To investigate the effects of dimensional changes on structural degradation, computational investigations with both support conditions were repeated with a longer plate. The length of the composite plate was increased from 4 to 6 in. while all other properties were kept the same. The finite element model for this longer geometry is shown in figure 11 . The number of finite elements were increased to keep the element sizes similar to that of the shorter model. Normalized degradation curves for support condition 1 are plotted in figure 12. The degradation curves depicted in figure 12 show characteristics similar to figure 2 , which was for the shorter model with the same boundary conditions and identical composite laminate configuration. As it was for the shorter plate, there is no structural degradation up to the application of approximately 70 percent of the ultimate fracture load. After the initiation of structural damage, the general character of the degradation curves are similar; however, there are some differences because of the change in geometry. The second and third natural frequencies degrade identically in this case, and the buckling instability is reached before complete 
structural fracture. The early instability may be expected from a longer specimen. However, to explain the identical degradation of the second and third natural frequencies, we will have to examine the corresponding mode shapes.

Figure 13 shows the mode shapes for the first three freevibration modes and the first buckling mode before loading under support condition 1. The second and third vibration modes both have their controlling wavelengths approximately in the transverse direction of the plate; in fact, vibratory wave direction at the center of the plate appears to be perpendicular to the orientation of the outer layer fibers for these two modes. The second and third vibration modes degrade identically because both are influenced only by the transverse properties of the plate at the early stages of damage. On the other hand, the first vibration mode and the fundamental buckling mode are influenced more by the longitudinal properties and the overall geometry of the model.

Figure 14 shows the same mode shapes at 91 percent of the ultimate fracture load. Similar to the case of the shorter model, the central notch extends in the transverse direction when the elements adjacent to the notch fail. Also similar to the shorter model under the same boundary conditions, there does not appear to be any significant change in the mode shapes at this stage of loading.

Figure 15 shows the mode shapes after 95 percent of the ultimate fracture load has been applied. There is additional damage and failure at the central notch of the model. The second vibration mode switches to a transverse wave pattern because of the weakening of the center of the plate and increased structural decoupling of the two sides separated by the central notch. The other three mode shapes that are depicted do not appear to be significantly affected by the weakness of the center. However, any additional loading causes rapid structural deterioration and disintegration of the plate model.

Figure 16 shows the normalized degradation curves for the buckling load and natural frequencies for the same 3- by 6-in. plate, but now simply supported on all four edges (support condition 2). As in the previously studied cases with the same material, structural degradation begins after 70 percent of the ultimate fracture load is applied. However, once degradation is initiated, the behavior differs from the other cases. The buckling load increases early with structural damage because of the higher tendency of the two halves of the plate to behave independently. The order of vibratory mode frequencies is changed as it was in the shorter model under support condition 2 .

To study the effects of the relative stiffnesses of the fiber and matrix on the composite structure, we analyzed an S-glass/HMHS laminate (laminate of S-glass fibers with a highmodulus, high-strength matrix). This time we used a more congruent modular ratio and the 3 - by 6 -in. computational model under support condition 1. Degradation curves for investigated structural properties are shown in figure 17 . The results are, in general, similar to those for the T-300/Epoxy composite except that, in the S-glass/HMHS composite, structural damage was more uniformly distributed exhibiting a more nonlinear behavior with smoother degradation curves. In addition, higher frequency modes were more severely affected near the ultimate load for the S-glass/HMHS composite.

\section{Discussion and Conclusions}

The present version of CODSTRAN was constructed from previously validated computational modules, accordingly the results are expected to be reliable predictions for the progressive fracture and degradation of composite structures.

According to computational predictions and general observations of depicted structural response characteristics, overall mechanical properties of the plate structure are most strongly influenced by composite fiber orientations and boundary conditions. Dimensional variations play a less important role; yet, there are perceivable changes in modal behavior when dimensional changes are accompanied by overconstrained boundary conditions. For example, changing the plate length from 4 to 6 in. under support condition 2 has a more significant influence on modal behavior than it does under support condition 1.

The variation in the detailed composite behavior in the limited examples examined in this report indicates that general conclusions regarding the behavior of damaged composites remain elusive: there is no simple generalization or rule relating the degraded structural characteristics of damaged angle-plied composite structures to the actual amount of damage present in the composite material. Accordingly, the necessity of reliable computational composite mechanics to predict the significant structural behavior patterns for each material, laminate, fiber orientation, geometry, boundary condition, and loading of a composite structure is reacknowledged.

\section{References}

1. Chamis, C.C.; Sinclair, J.H.; and Lark, R.F.: Dynamic Response of Damaged Angleplied Fiber Composites. NASA TM-79281, 1979.

2. Chamis, C.C.; and Williams, G.C.: Interply Layer Degradation Effects on Composite Structural Response. J. Aircraft, vol. 22, no. 7, July 1985, pp. 573-580.

3. Chamis, C.C.; and Smith, G.T.: CODSTRAN: Composite Durability Structural Analysis. NASA TM-79070, 1978.

4. Irvine, T.B.; and Ginty, C.A.: Progressive Fracture of Fiber Composites. NASA TM-83701, 1983.

5. Murthy, P.L.N.; and Chamis, C.C.: ICAN: Integrated Composites Analyzer. J. Compos. Technol. Res., vol. 8, no. 1, Spring 1986, pp. 8-17.

6. Murthy, P.L.N.; and Chamis, C.C.: Integrated Composite Analyzer (ICAN): Users and Programmers Manual. NASA TP-2515, 1986.

7. Nakazawa, S.: MHOST Version 4.2, Vol. 1, User's Manual. NASA CR-182235, 1989.

8. McCormick, C.W., ed.: NASTRAN User's Manual (level 15). NASA SP-222(01), 1972 


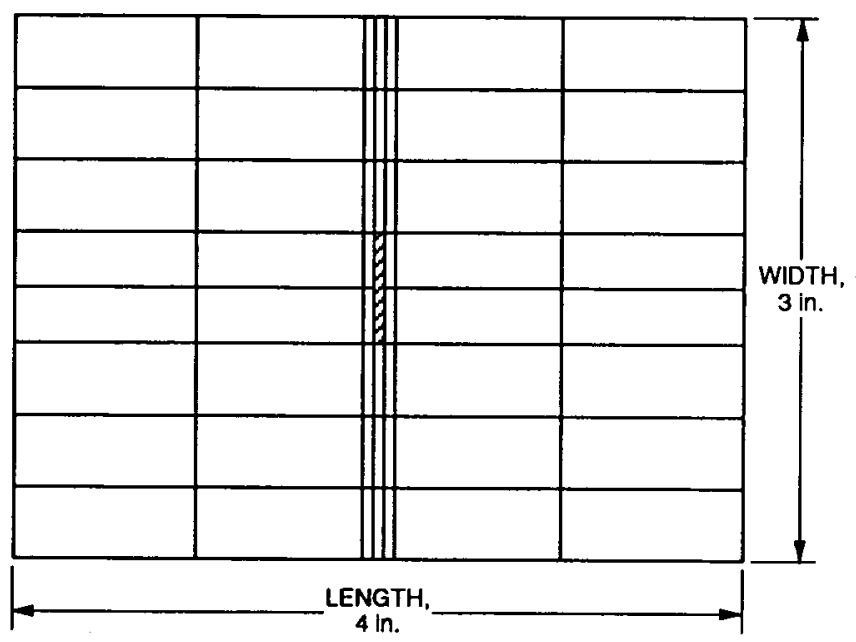

Figure 1.-Composite plate finite element model.

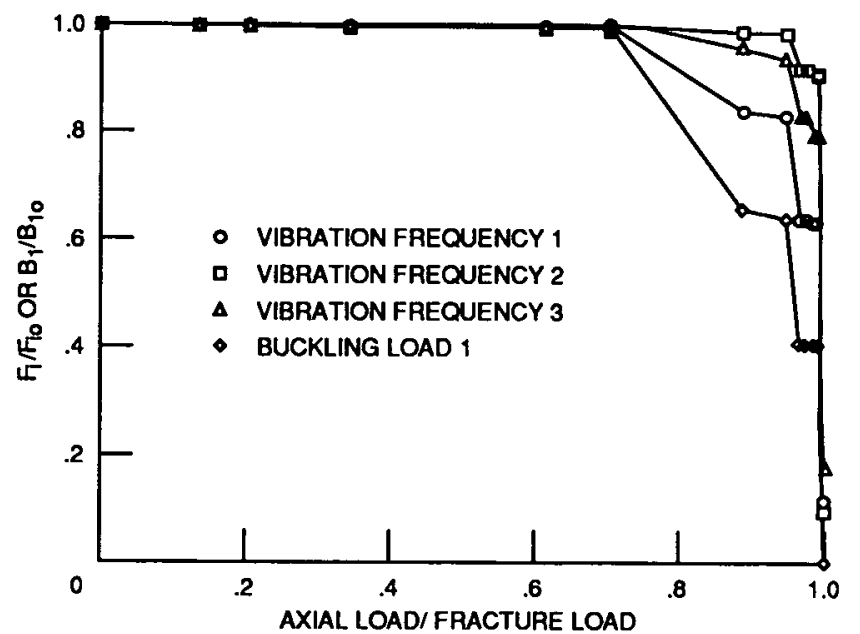

Figure 2.-Structural degradation for composite plate; support condition 1. 


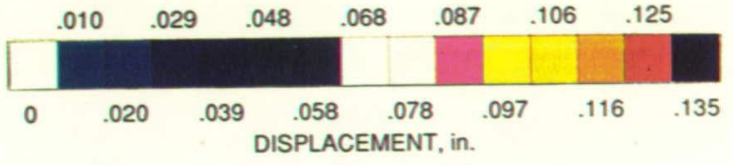

FREE

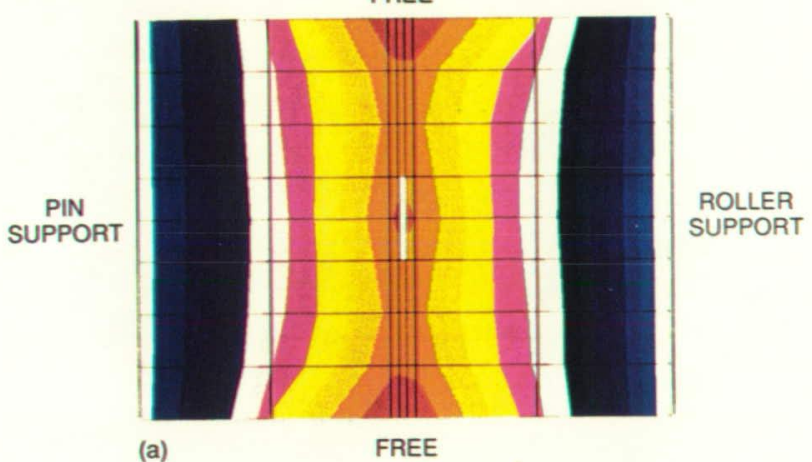

(a)

FREE
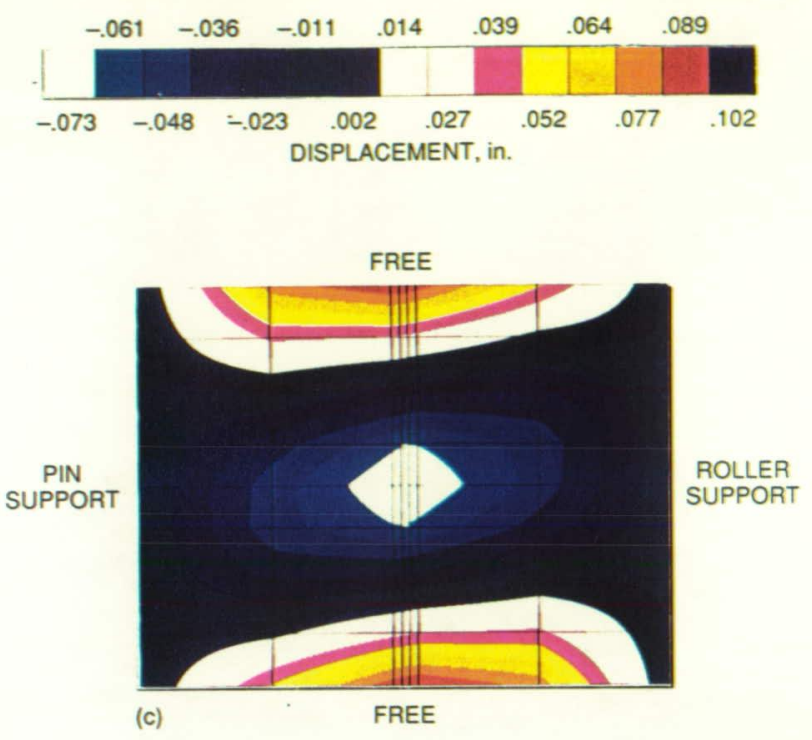

(c)
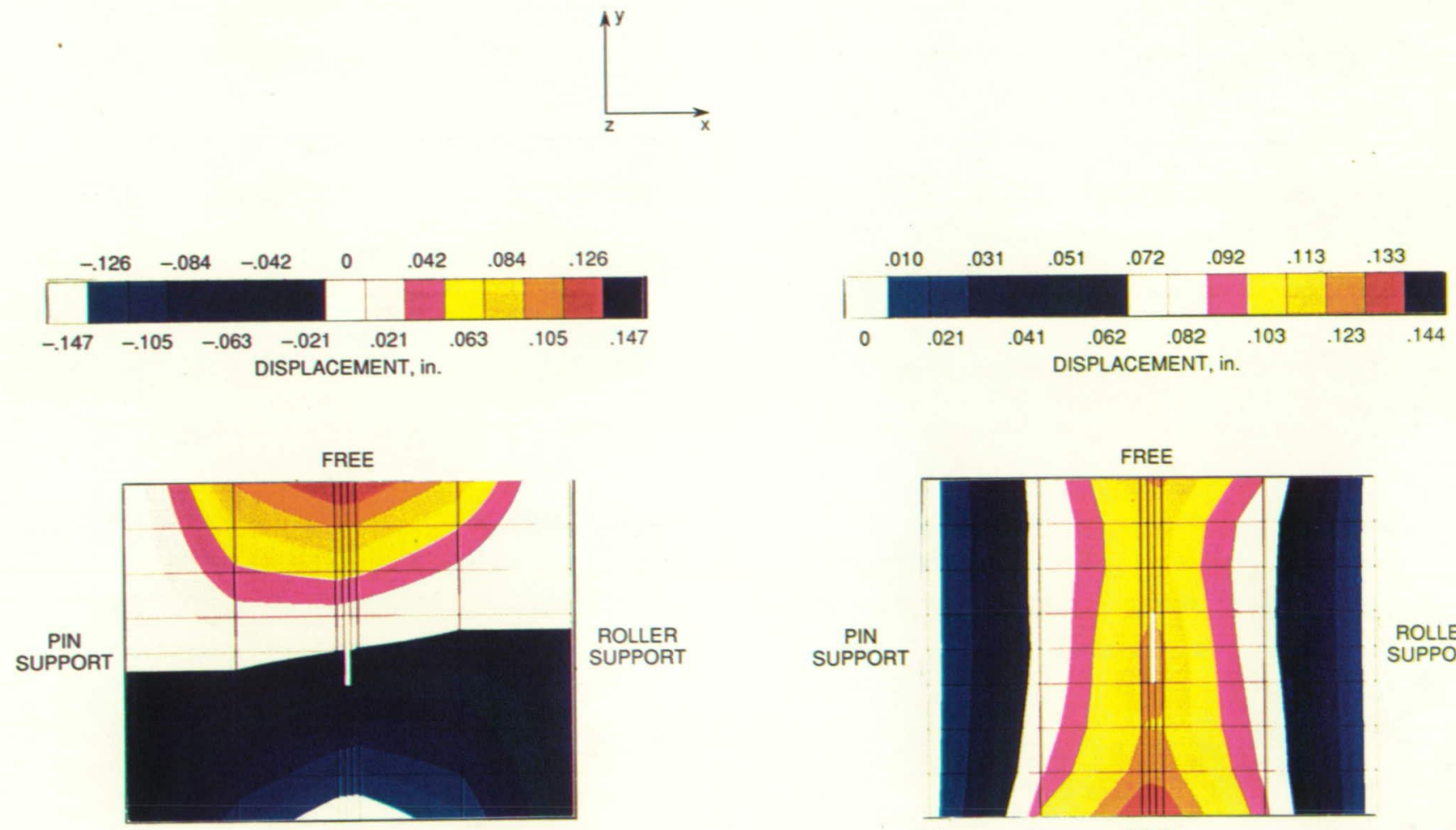

(b)

FREE

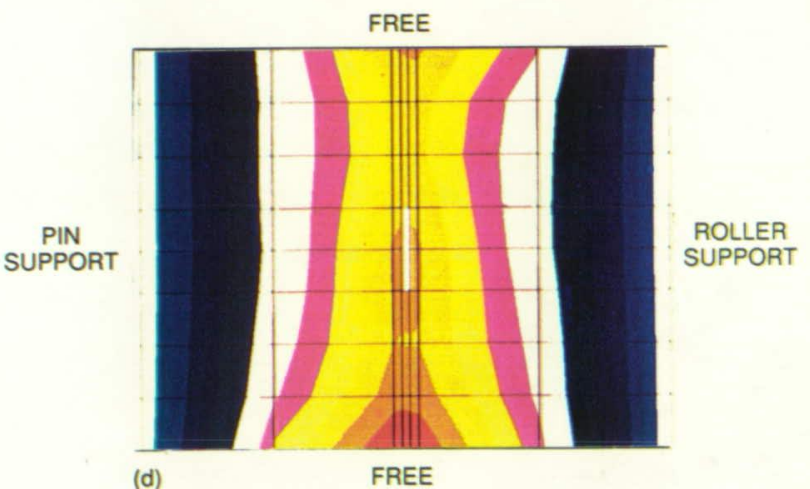

(a) Vibration mode $1 . \quad$ (c) Vibration mode 3.

(b) Vibration mode 2. $\quad$ (d) Buckling mode 1.

Figure 3.-Mode shape fringes before loading. Fracture load, $5889 \mathrm{lb}$; support condition 1. 

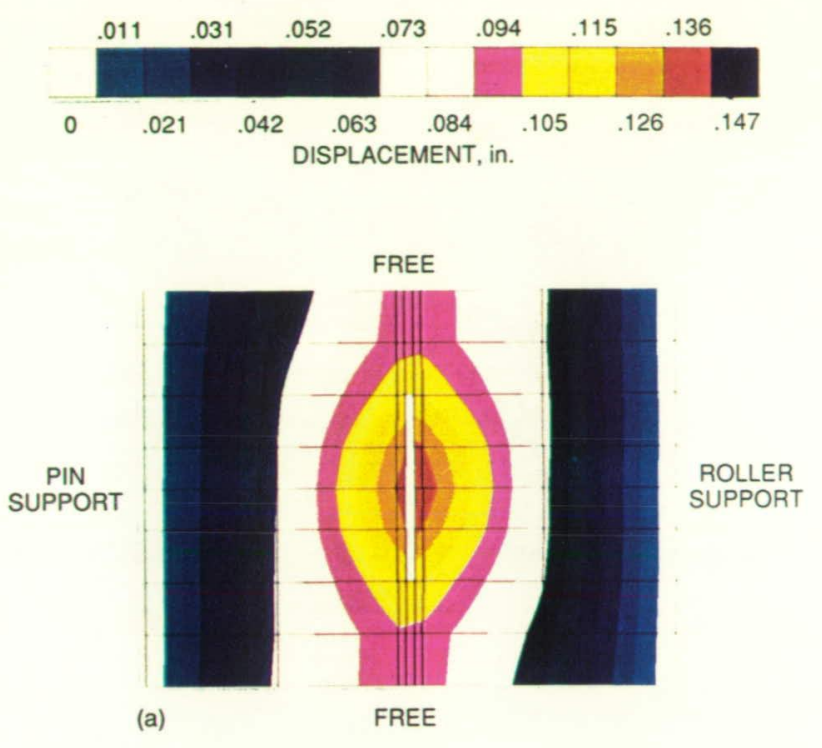

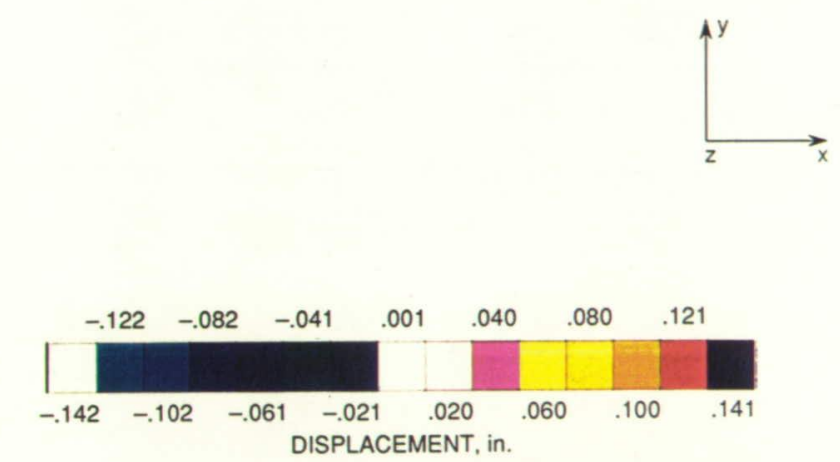

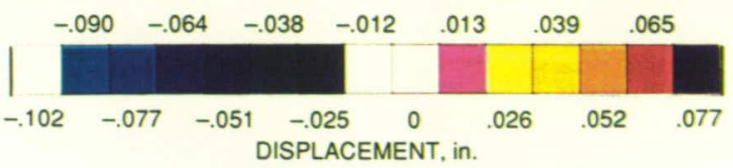

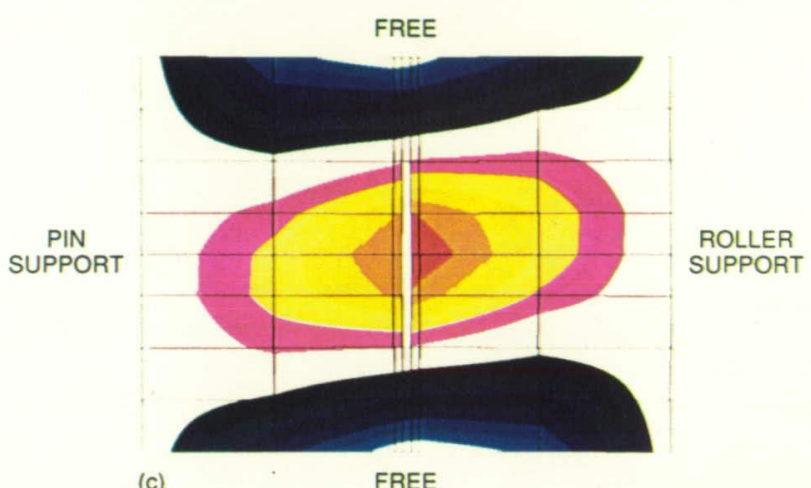

(c)

FREE

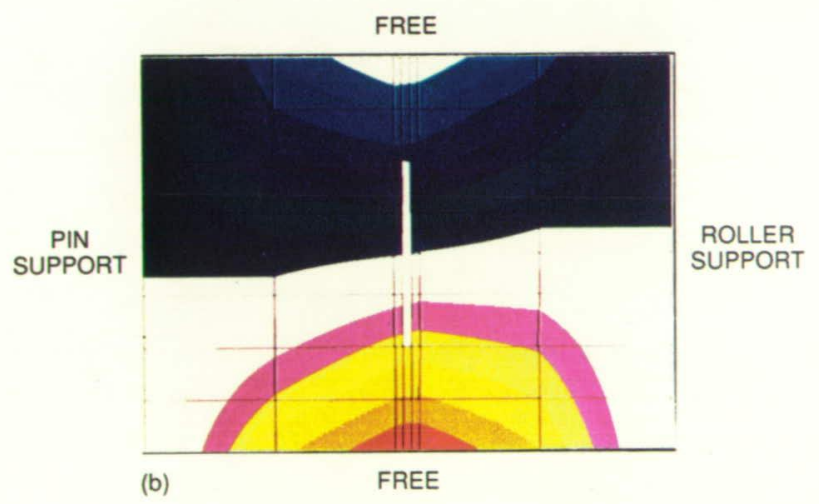

(a) Vibration mode 1.

(b) Vibration mode 2.

(c) Vibration mode 3.
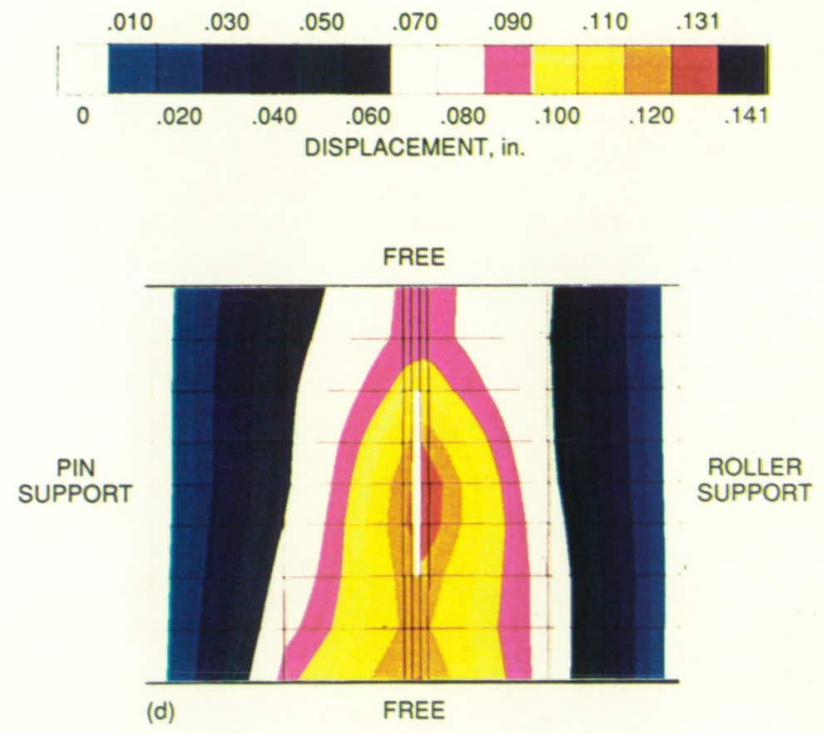

(d) Buckling mode 1 .

Figure 4.-Mode shape fringes after 94 percent loading. Fracture load, $5889 \mathrm{lb}$; support condition 1. 

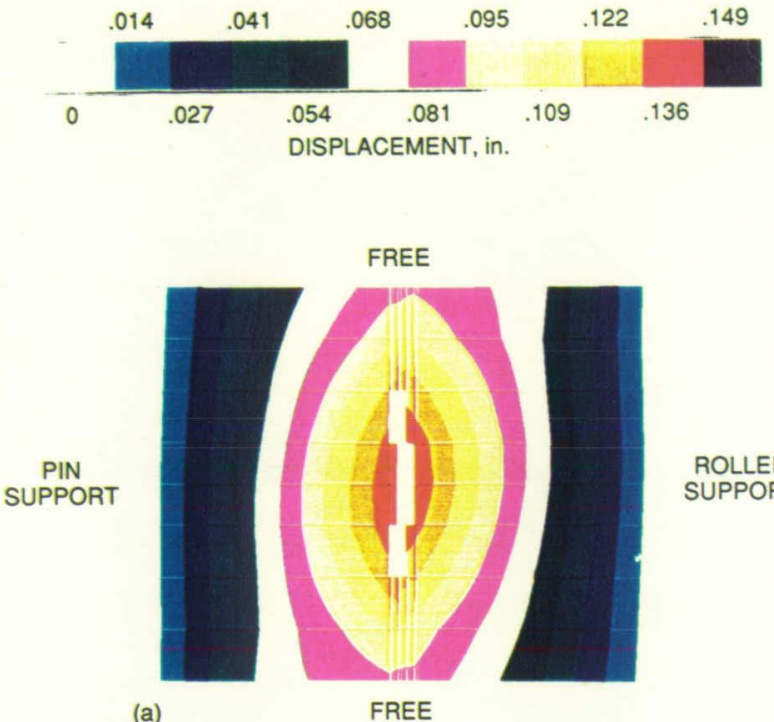

(a)

FREE
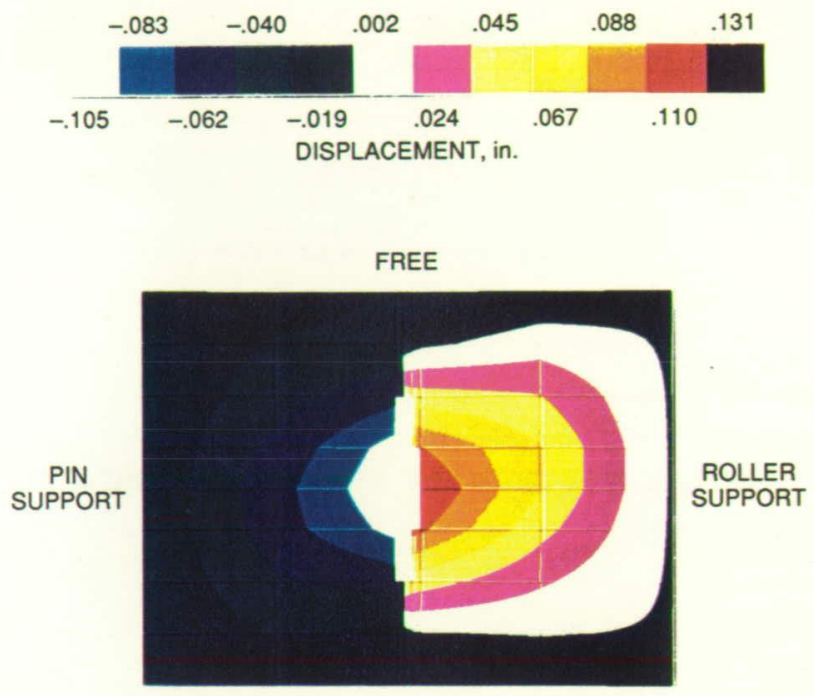

(c)
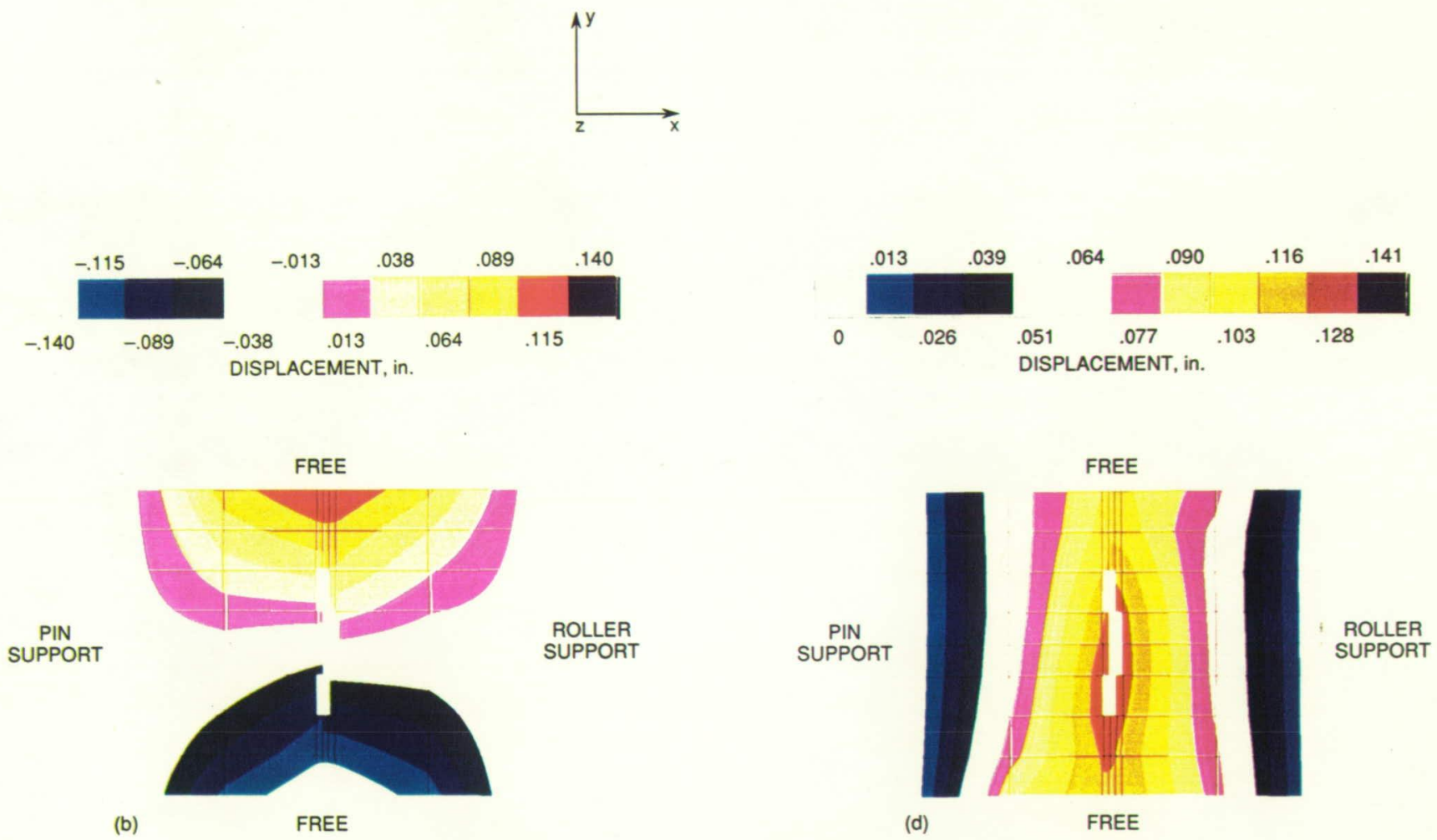
(a) Vibration mode 1 .
(b) Vibration mode 2.
(c) Vibration mode 3 .
(d) Buckling mode 1 .

Figure 5.-Mode shape fringes after 97 percent loading. Fracture load, $5889 \mathrm{lb}$; support condition 1. 


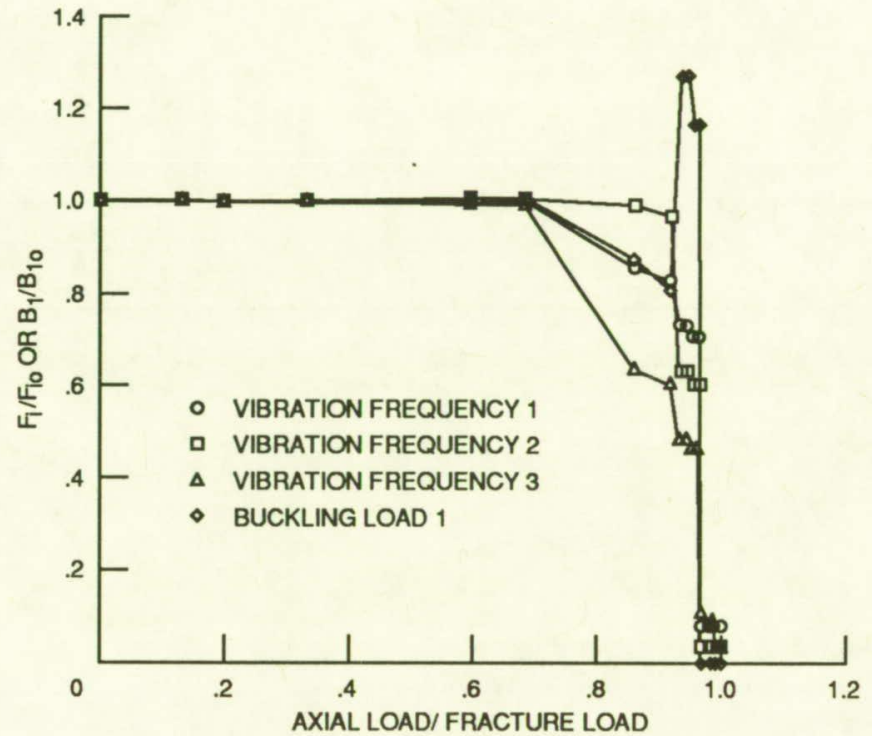

Figure 6.-Structural degradation for short plate; support condition 2. 

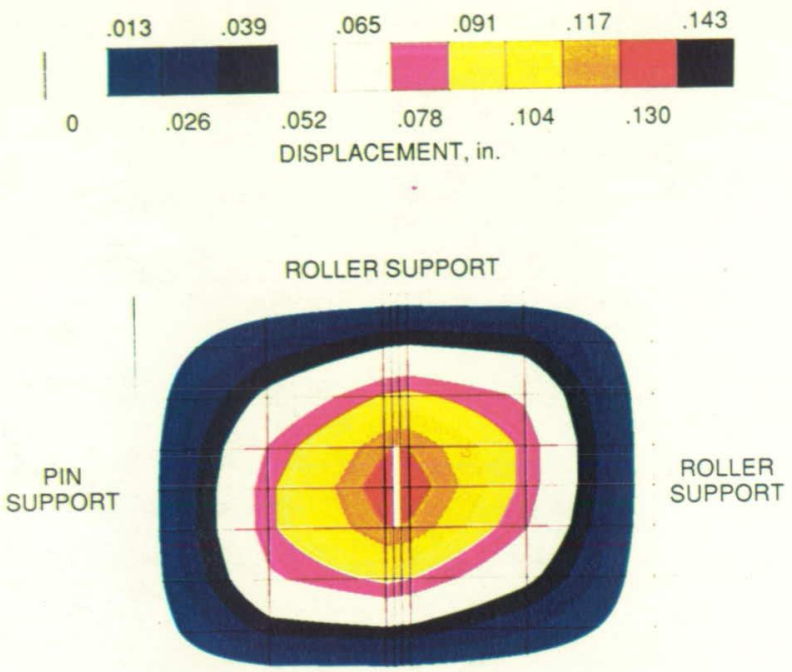

(a)

ROLLER SUPPORT
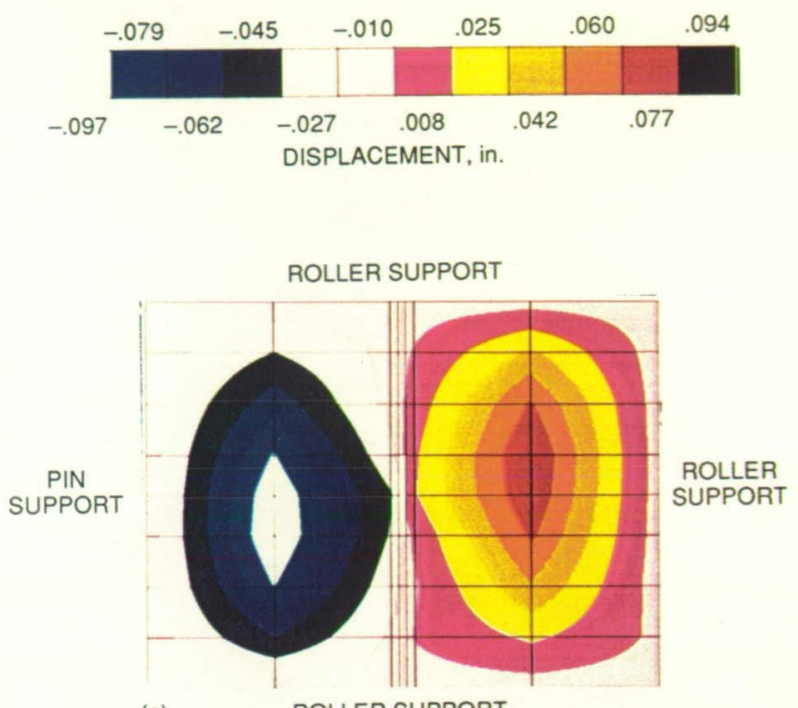

(c)
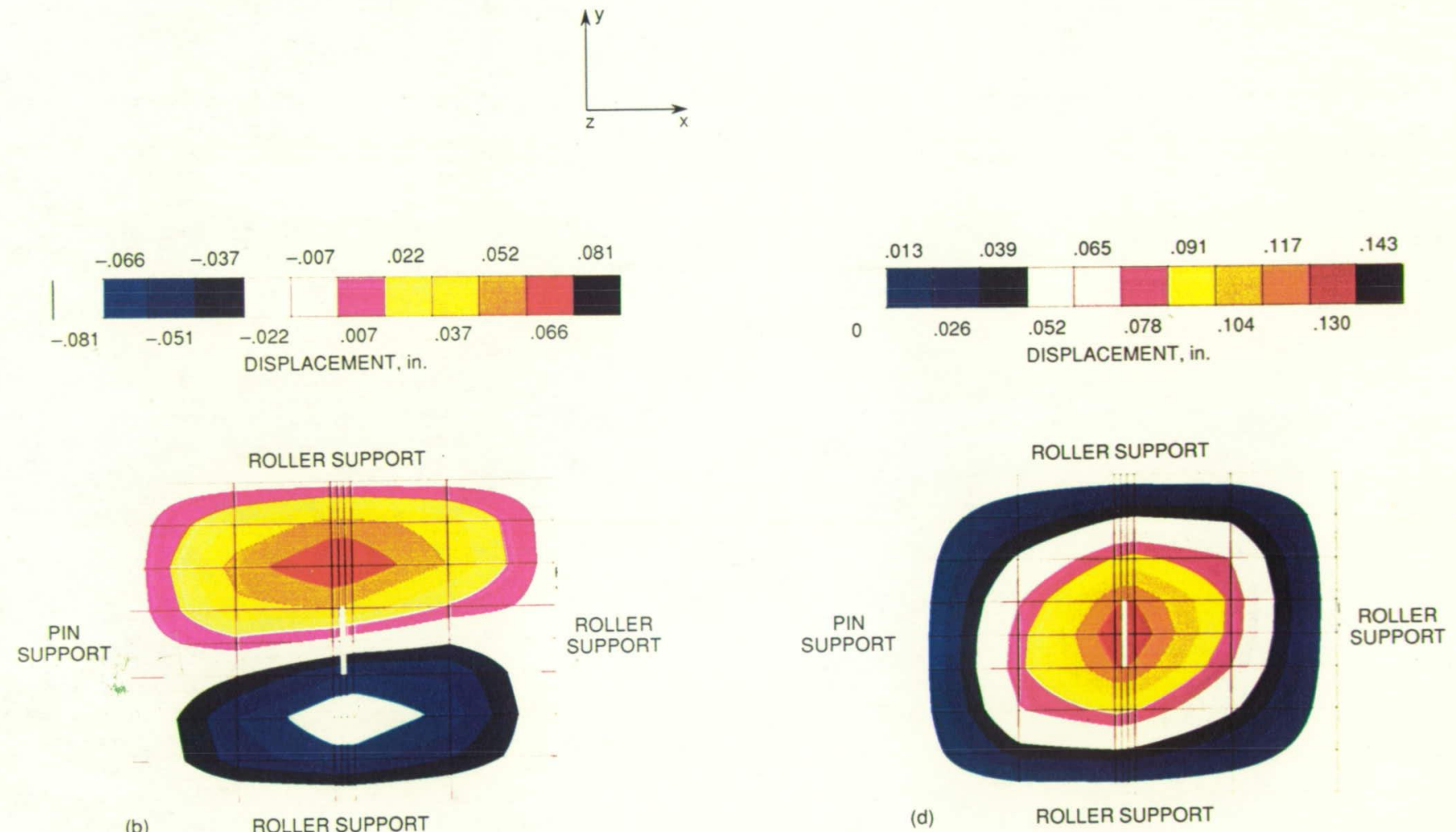

(b)

ROLLER SUPPORT

(d)

(c) Vibration mode 3 .

(a) Vibration mode 1

(b) Vibration mode 2.

(d) Buckling mode 1 .

Figure 7.-Mode shape fringes before loading. Fracture load, $6082 \mathrm{lb}$; support condition 2. 


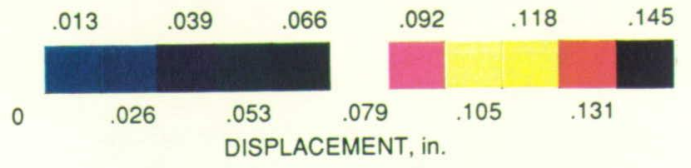

ROLLER SUPPORT

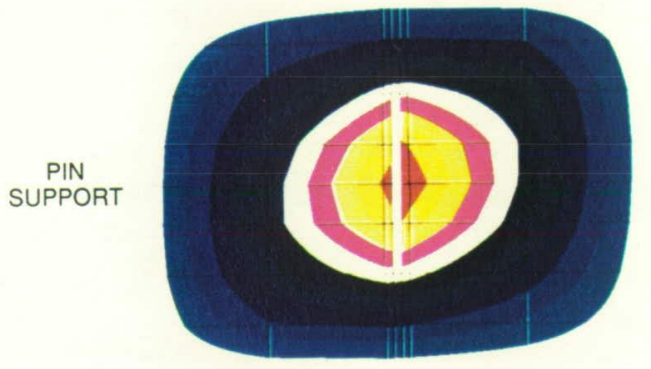

(a)

ROLLER SUPPORT

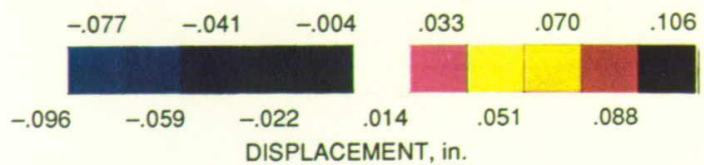

ROLLER

SUPPORT
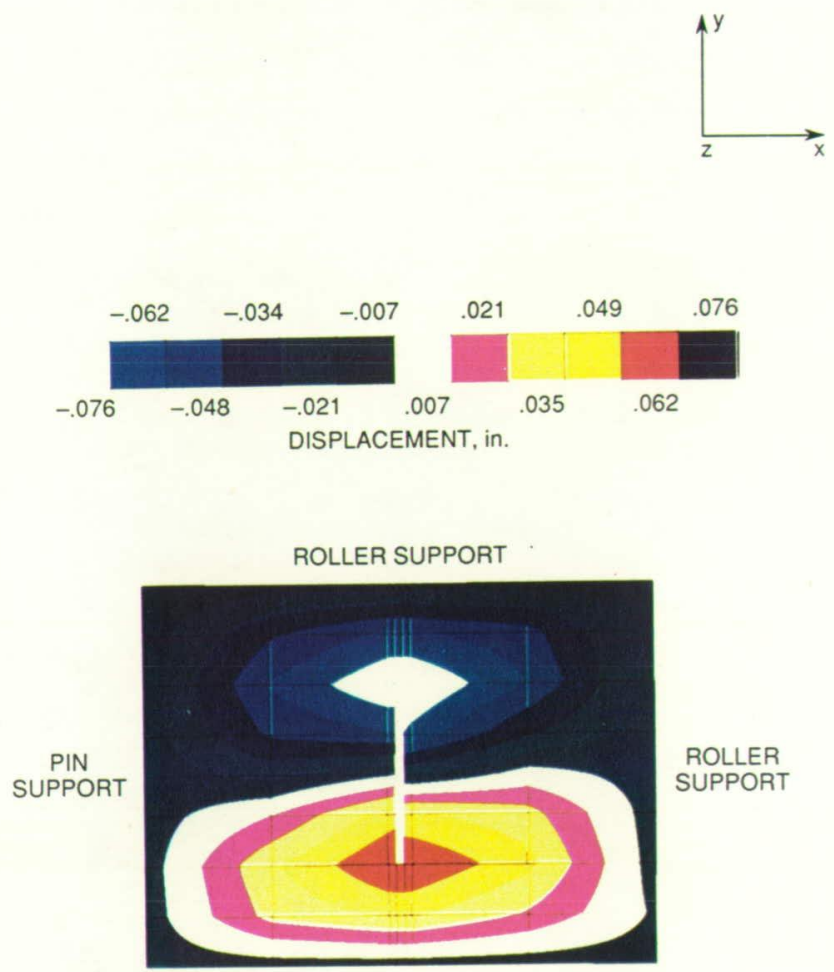

(b)

ROLLER SUPPORT

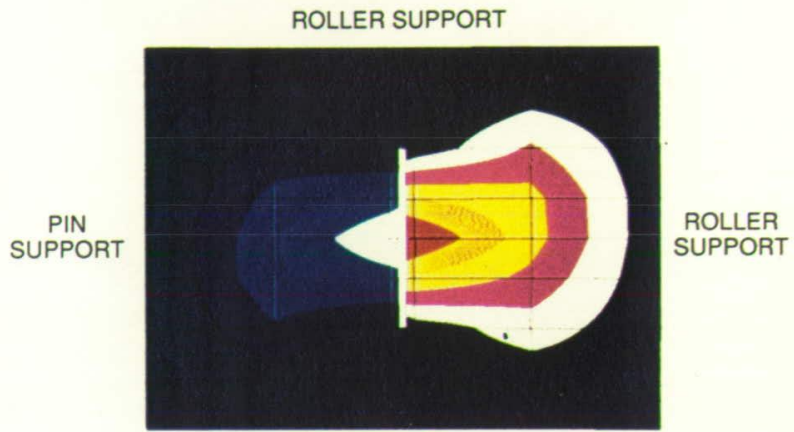

(c) ROLLER SUPPORT
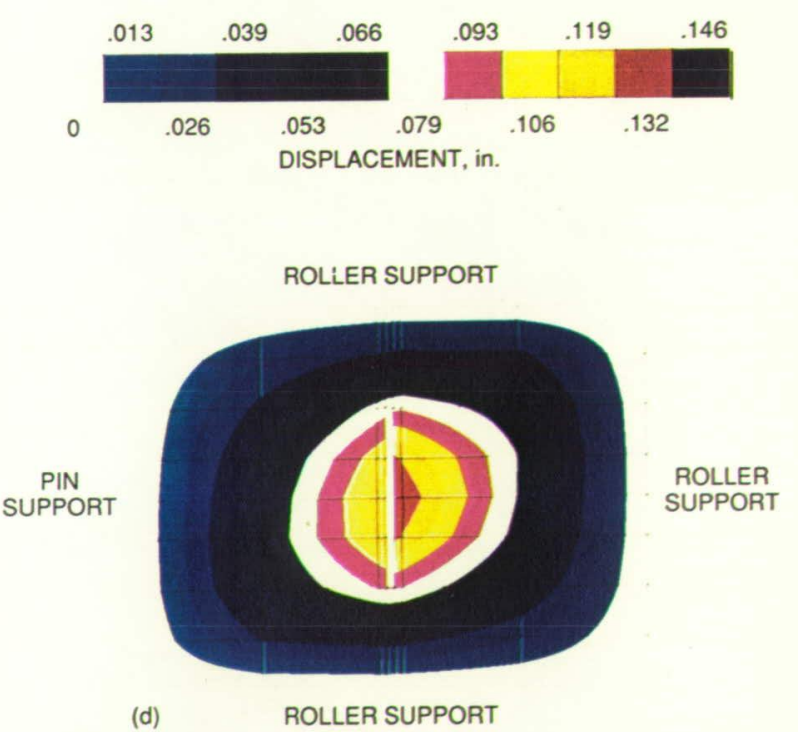

(a) Vibration mode 1 .

(b) Vibration mode 2

(c) Vibration mode 3 .

(d) Buckling mode 1 .

Figure 8.-Mode shape fringes after 91 percent loading. Fracture load, $6082 \mathrm{lb}$; support condition 2. 

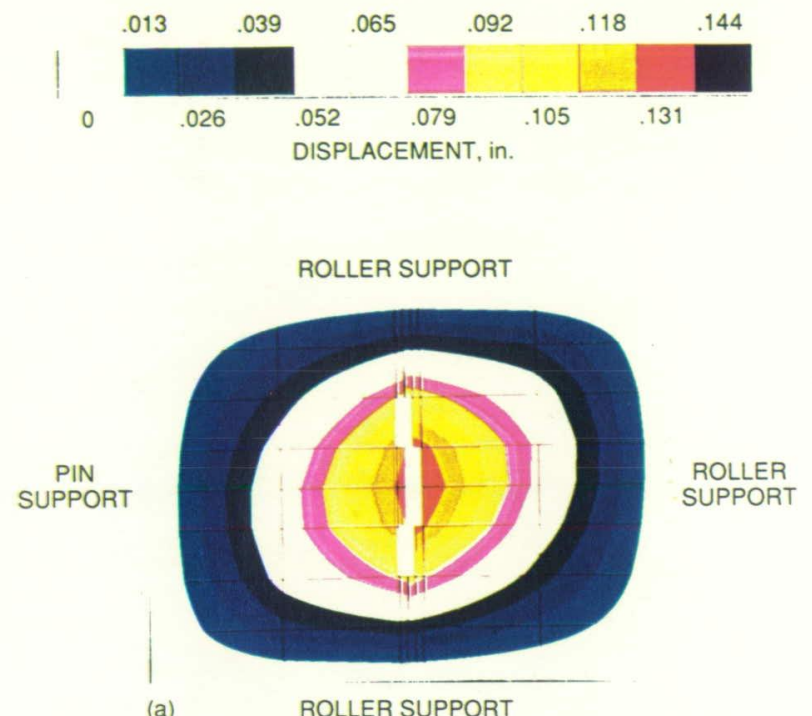

(a) ROLLER SUPPORT
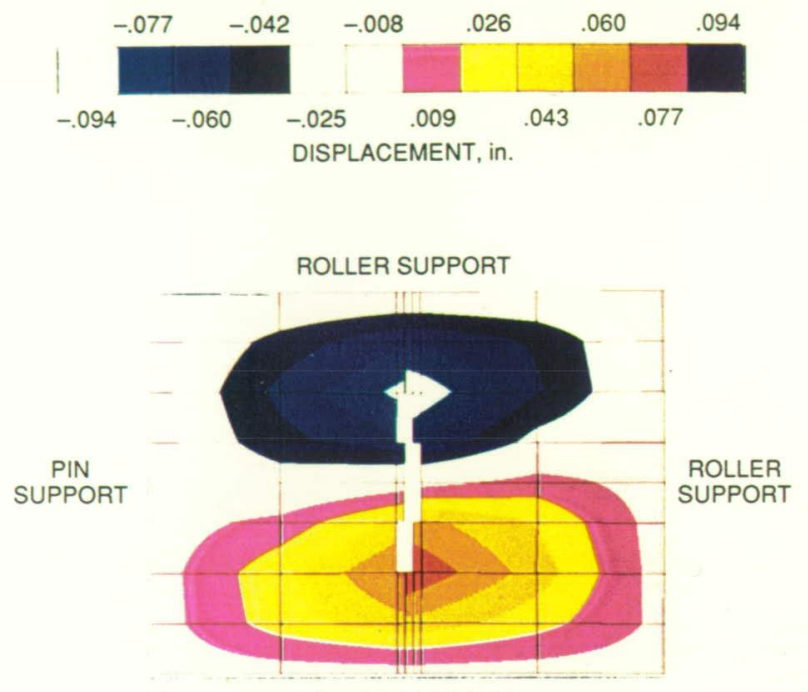

(c)

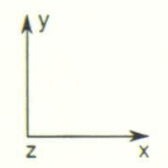

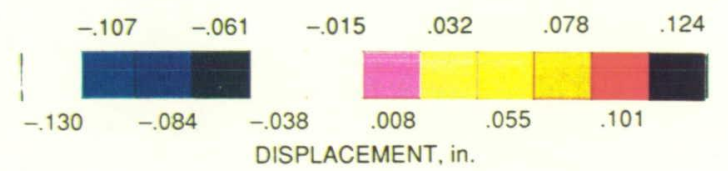

ROLLER SUPPORT

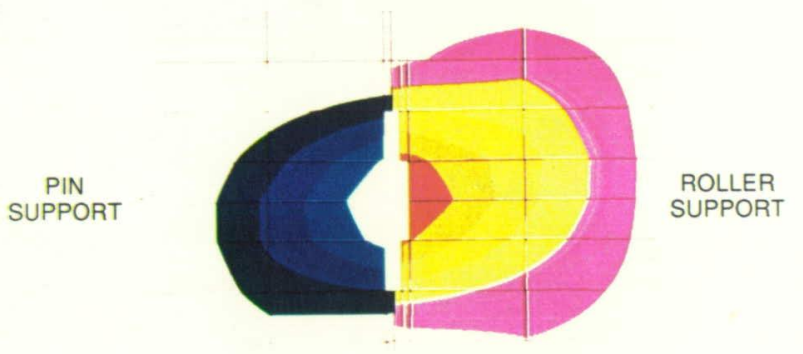

(b)

$$
\text { ROLLER SUPPORT }
$$

$\begin{array}{lc}\text { ROLLER } & \text { PIN } \\ \text { SUPPORT } & \text { SUPPORT }\end{array}$
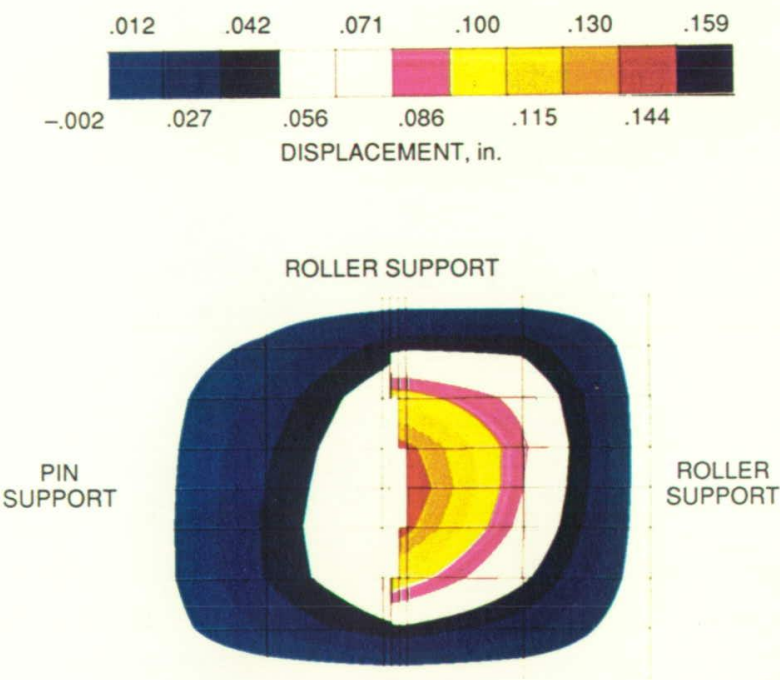

(d)

ROLLER SUPPORT

(a) Vibration mode $1 . \quad$ (c) Vibration mode 3.

(b) Vibration mode $2 . \quad$ (d) Buckling mode 1.

Figure 9.-Mode shape fringes after 94 percent loading. Fracture load, $6082 \mathrm{lb}$; support condition 2. 

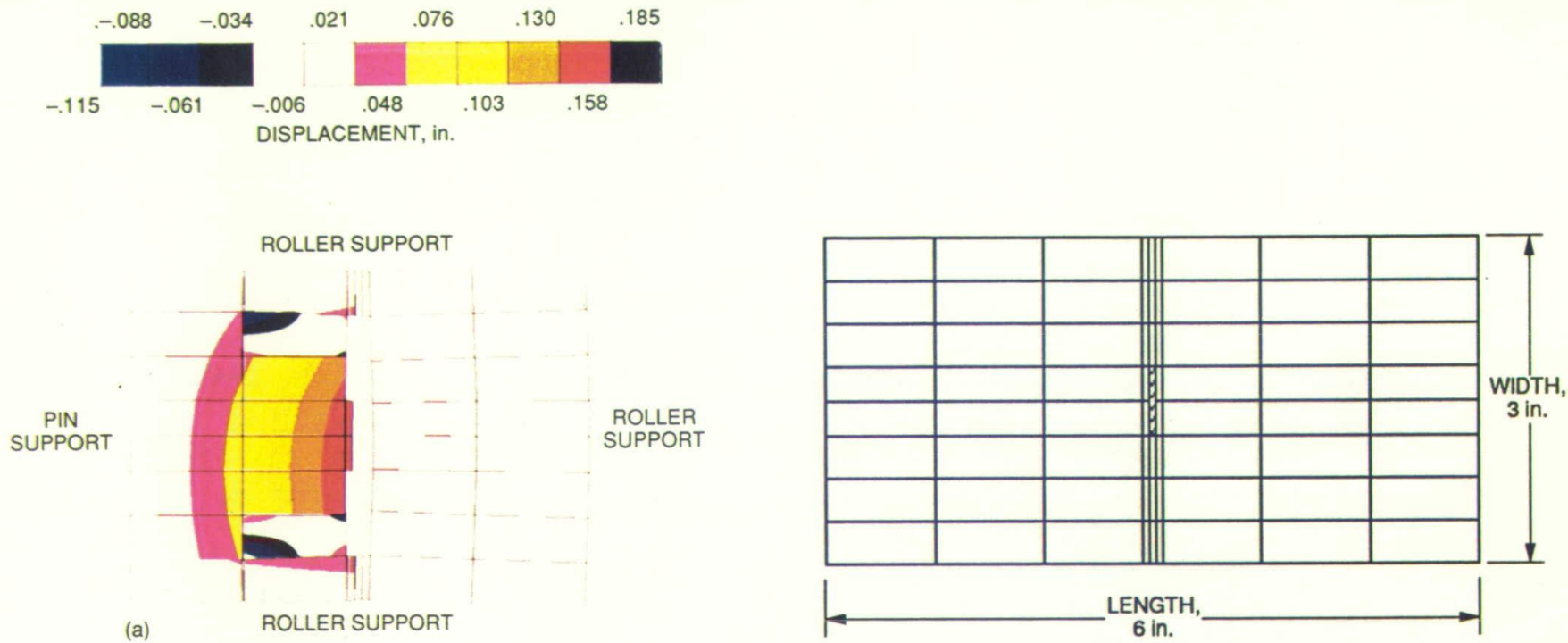

Figure 11.-Long plate finite element model.
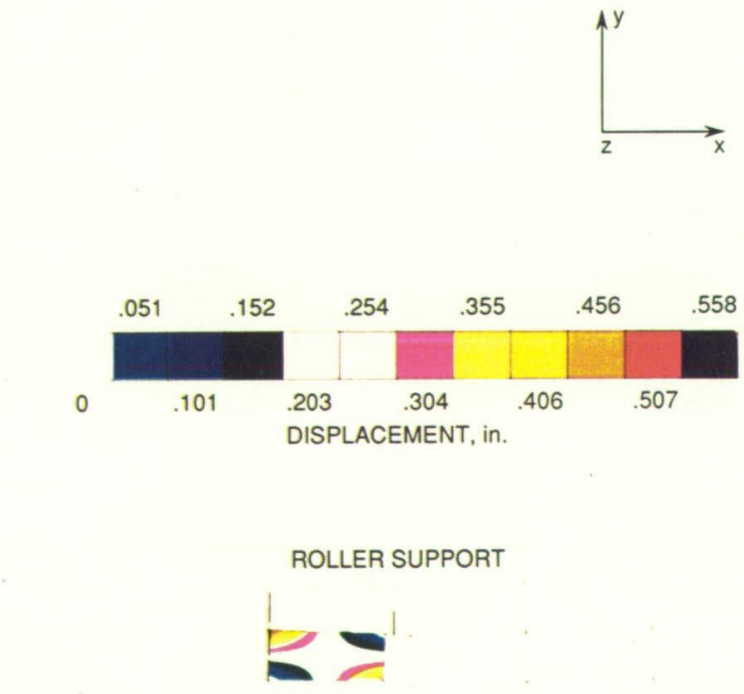

PIN

SUPPORT

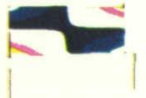

(b)

ROLLER SUPPORT

(a) Vibration mode 3 .

(b) Buckling mode 1 .

Figure 10.-Mode shape fringes after 98 percent loading. Fracture load, $6082 \mathrm{lb}$; support condition 2 .

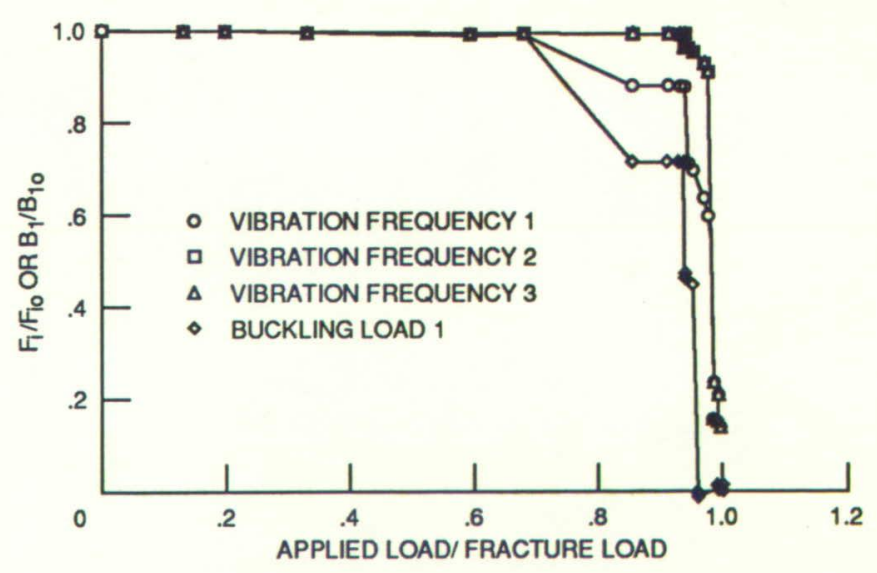

Figure 12.-Structural degradation for long plate; support condition 1. 

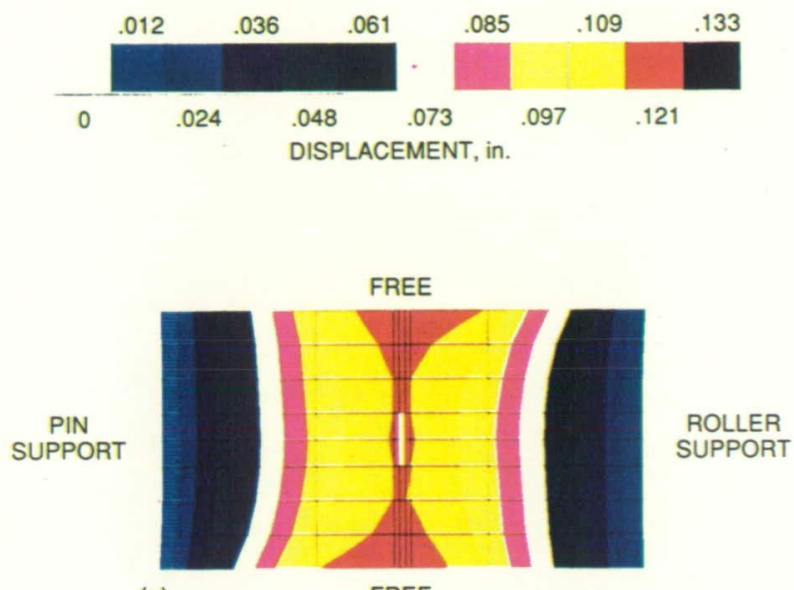

(a)

FREE
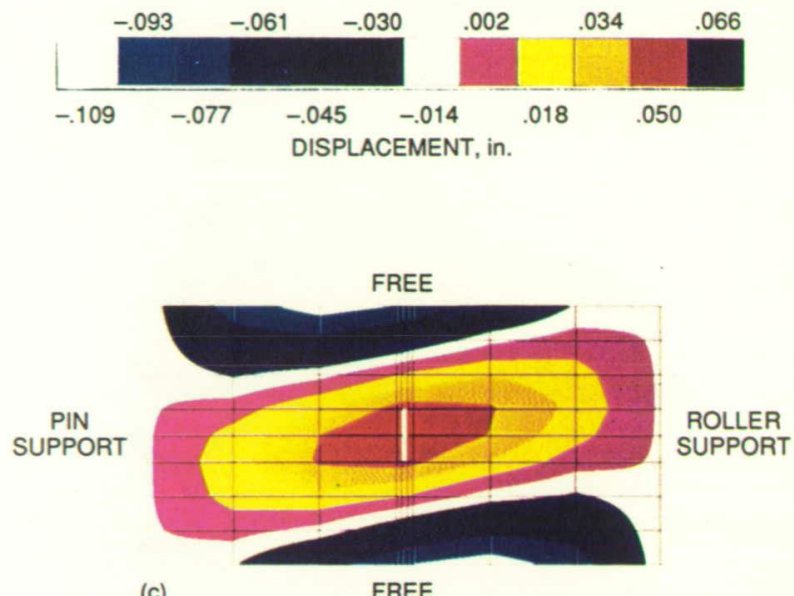

(c)

FREE
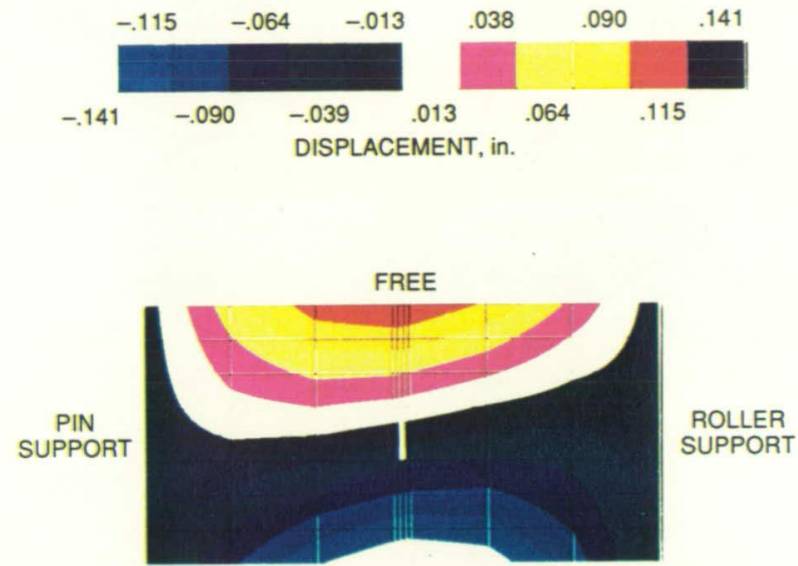

(b)

FREE
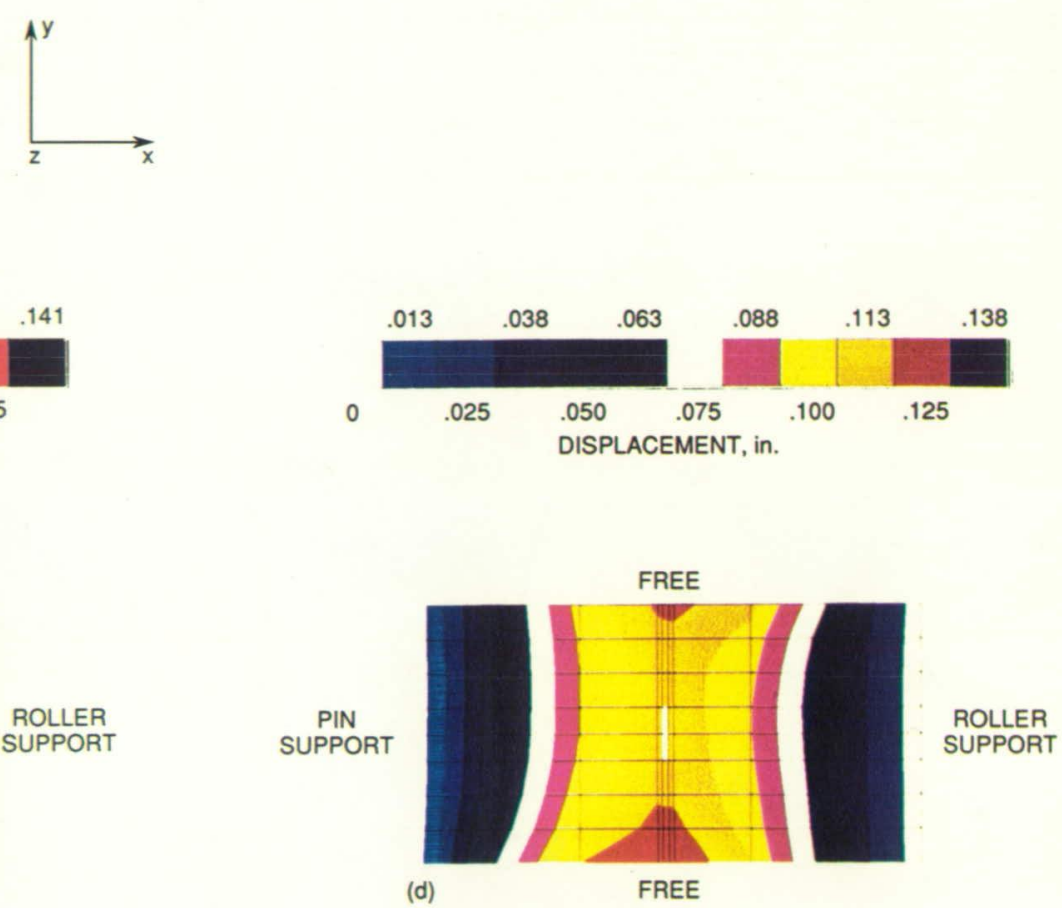
(a) Vibration mode 1 .
(b) Vibration mode 2
(c) Vibration mode 3.
(d) Buckling mode 1 .

Figure 13.-Mode shape fringes before loading. Fracture load, $6086 \mathrm{lb}$; support condition 1. 

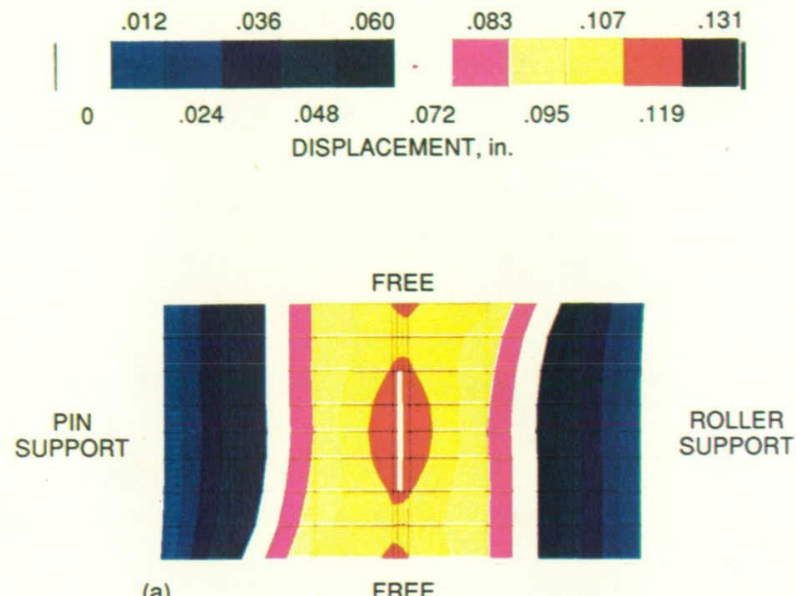

(a)

FREE
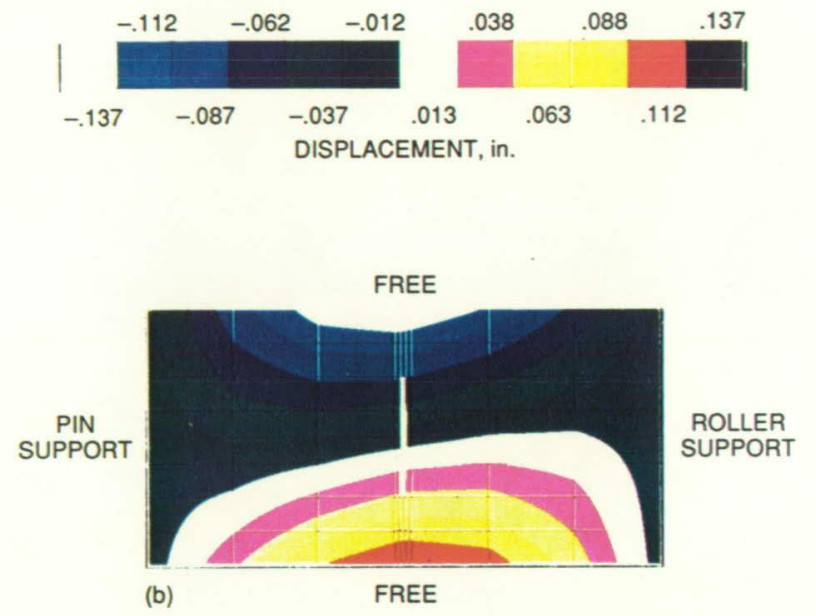

(a) Vibration mode 1 .

(b) Vibration mode 2 .
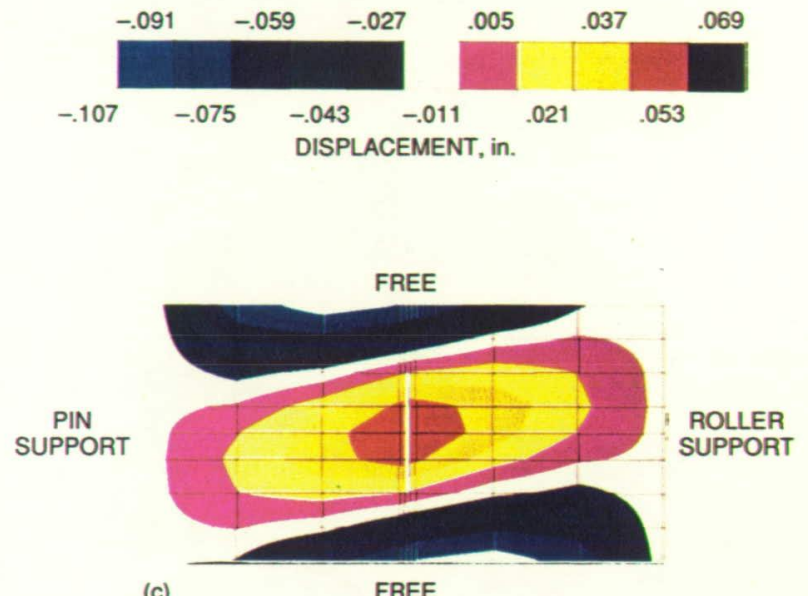

(c)

FREE

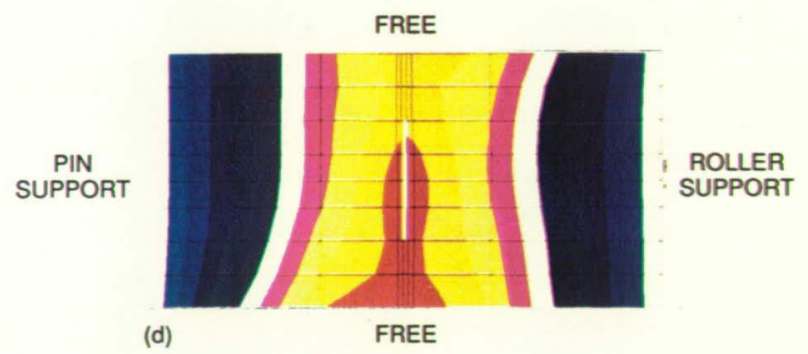

(c) Vibration mode 3 .

(d) Buckling mode 1 .

Figure 14.-Mode shape fringes after 91 percent loading. Fracture load, $6086 \mathrm{lb}$; support condition 1. 

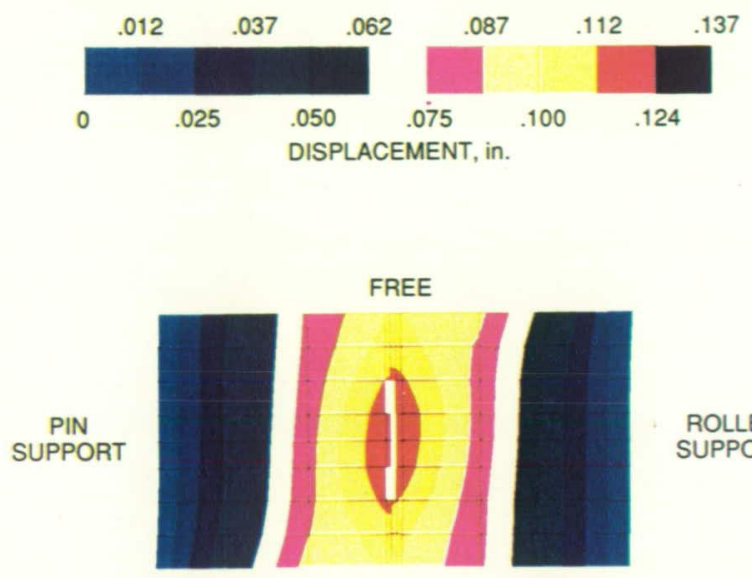

(a)

FREE
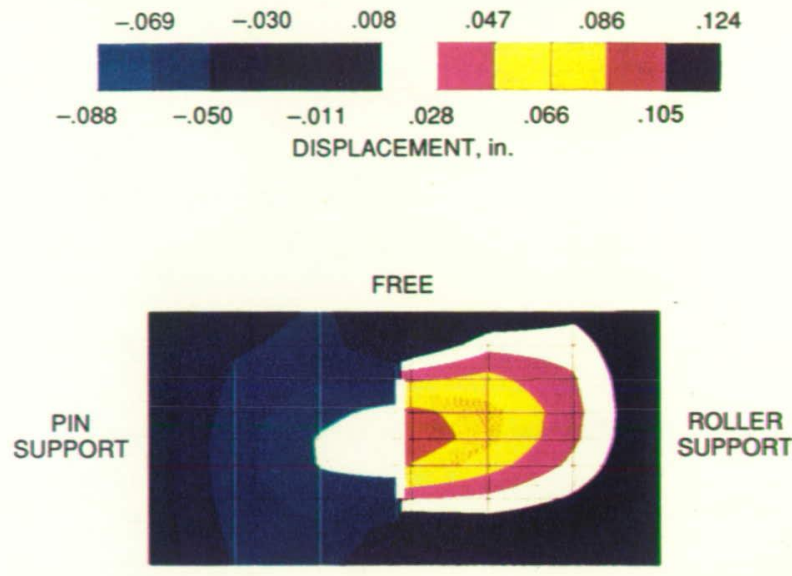

(c)
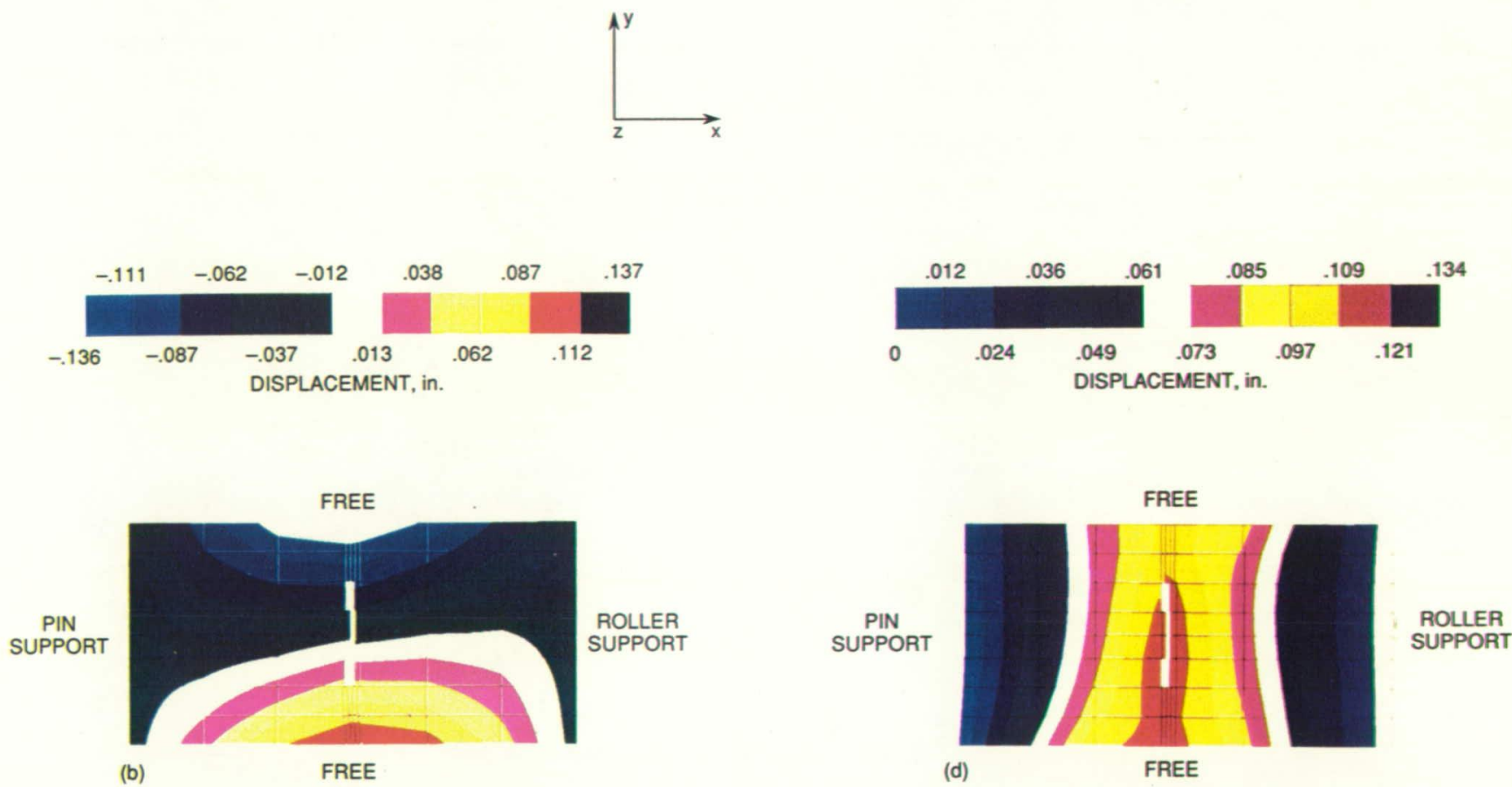

(a) Vibration mode 1 .

(b) Vibration mode 2 .

(c) Vibration mode 3 .

(d) Buckling mode 1 .

Figure 15.-Mode shape fringes after 95 percent loading. Fracture load 6086 lb; support condition 1. 


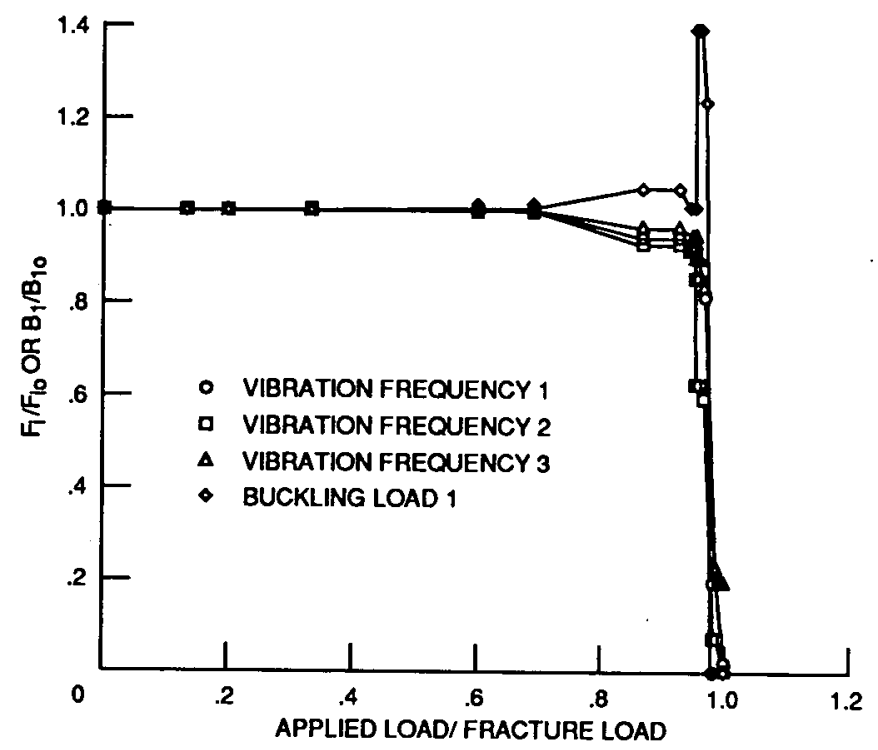

Figure 16.-Structural degradation for long plate; support condition 2.

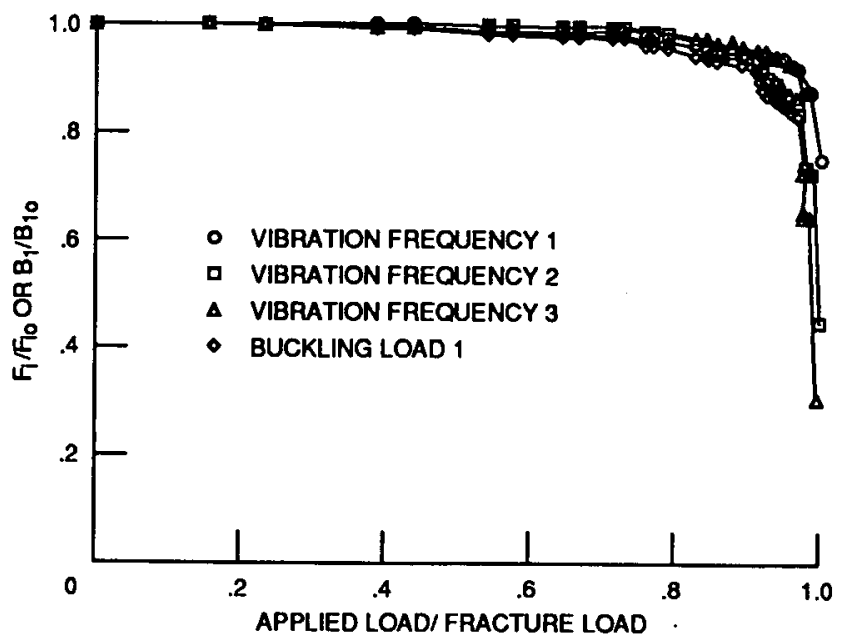

Figure 17.-Structural degradation for S-glass/HMHS plate; support condition 1. 


\begin{tabular}{|c|c|c|}
\hline \multicolumn{3}{|c|}{ Report Documentation Page } \\
\hline $\begin{array}{l}\text { 1. Report No. } \\
\text { NASA TM-102370 }\end{array}$ & 2. Government Accession No. & 3. Recipient's Catalog No. \\
\hline \multirow{2}{*}{\multicolumn{2}{|c|}{$\begin{array}{l}\text { 4. Title and Subtitle } \\
\text { Structural Behavior of Composites With Progressive Fracture }\end{array}$}} & $\begin{array}{l}\text { 5. Report Date } \\
\text { January } 1990\end{array}$ \\
\hline & & 6. Performing Organization Code \\
\hline \multirow{2}{*}{\multicolumn{2}{|c|}{$\begin{array}{l}\text { 7. Author(s) } \\
\text { Levon Minnetyan, Christos C. Chamis, and Pappu L.N. Murthy }\end{array}$}} & $\begin{array}{l}\text { 8. Performing Organization Report No. } \\
\text { E-5089 }\end{array}$ \\
\hline & & $\begin{array}{c}\text { 10. Work Unit No. } \\
505-63-11\end{array}$ \\
\hline \multirow{2}{*}{\multicolumn{2}{|c|}{$\begin{array}{l}\text { 9. Performing Organization Name and Address } \\
\text { National Aeronautics and Space Administration } \\
\text { Lewis Research Center } \\
\text { Cleveland, Ohio } 44135-3191\end{array}$}} & 11. Contract or Grant No. \\
\hline & & 13. Type of Report and Period Covered \\
\hline \multirow{2}{*}{\multicolumn{2}{|c|}{$\begin{array}{l}\text { 12. Sponsoring Agency Name and Address } \\
\text { National Aeronautics and Space Administration } \\
\text { Washington, D.C. } 20546-0001\end{array}$}} & Technical Memorandum \\
\hline & & 14. Sponsoring Agency Code \\
\hline
\end{tabular}

15. Supplementary Notes

Levon Minnetyan, Clarkson University, Pottsdam, New York 13676; Christos C. Chamis and Pappu L.N. Murthy, NASA Lewis Research Center.

16. Abstract

Structural characteristics such as natural frequencies and buckling loads with corresponding mode shapes were investigated during progressive fracture of multilayer, angle-plied polymer matrix composites. A computer program was used to generate the numerical results for overall mechanical response of damaged composites. Variations in structural characteristics as a function of the previously applied loading were studied. Results indicate that most of the overall structural properties were preserved throughout a significant proportion of the ultimate fracture load. For the cases studied, changes in structural behavior began to occur after 70 percent of the ultimate fracture load had been applied. However, the individual nature of the structural change was rather varied depending on the laminate configuration, fiber orientation, and the boundary conditions.

17. Key Words (Suggested by Author(s))

Structural evaluation; Progressive fracture; Composites; Damage; Fracture; Computer simulation; Structural response; Computational mechanics
18. Distribution Statement

Unclassified - Unlimited

Subject Category 24

19. Security Classif. (of this report)

20. Security Classif. (of this page)

Unclassified

21. No. of pages

18
22. Price* 
National Aeronautics and Space Administration

Lewis Research Center

Cleveland, Ohio 44135

Official Business

Penalty for Private Use $\$ 300$

ADDRESS CORRECTION REQUESTED

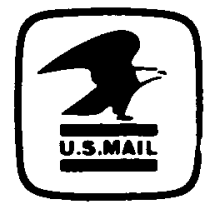

Postage and Fees Paid

Natonat Aeronautics ard

Space Adm nistration

VASA 45 